\title{
COMPARATIVE EVALUATION OF SMEAR LAYER REMOVAL, CALCIUM IONS LOSS AND DENTIN MICROHARDNESS AFTER DIFFERENT FINAL IRRIGATION SOLUTIONS
}

\author{
Reem Adel Abd-Elgawad* and Dalia Mukhtar Fayyad**
}

\begin{abstract}
Aim: The aim of this study was to evaluate the smear layer removal ability of three different irrigation solutions and their effect on calcium ion loss and dentin microhardness.

Materials and Methods: Forty root samples were used in this study. Samples were divided into four groups according to the type of irrigant used as a final rinse into: group A; 5.25\% Sodium hypochlorite $(\mathrm{NaOCl})$ (control), group B; 17\% Ethylenediamine tetraacetic acid (EDTA), group C; QMix 2in1, and group D; 0.2\% Chitosan. After final rinse the measurement of Ca ions loss was done using atomic absorption spectrophotometry. Then, samples were divided longitudinally into two halves. One half of each sample was evaluated for smear layer removal ability using Environmental Scanning Electron Microscope. The other half was examined for dentin microhardness using Vickers microhardness tester. Parametric data were analyzed by One Way ANOVA test then, Games-howell test and Tukey post-hoc test and none parametric data were analyzed by KruskalWallis and Dunn's test at $\mathrm{P} \leq 0.05$.
\end{abstract}

Results: $\mathrm{NaOCl}$ did not show any smear layer removal ability, while EDTA, QMix, and Chitosan showed complete smear layer removal and patent dentinal tubules particularly at the cervical third. EDTA, QMix, and Chitosan recorded the highest Ca ion loss and the lowest microhardness than $\mathrm{NaOCl}$.

Conclusion: EDTA, QMix, and Chitosan significantly removed smear layer and so released higher amount of $\mathrm{Ca}$ ion which adversely affect the microhardness. It remained difficult to completely remove smear layer from the apical third and so it recorded the highest microhardness.

KEY WORDS: Chitosan, EDTA, QMix, Ca ion loss, Microhardness, Smear layer.

\section{INTRODUCTION}

Nonsurgical root canal treatment is a prospective procedure for saving teeth that otherwise would be extracted. Adequate cleaning and shaping of the root canal system is the golden key for establishing best possible results of the treatment ${ }^{1}$. Endodontic

*Lecturer in Endodontics, Faculty of Dentistry, Suez Canal University

**Associate professor of Endodontics, Faculty of Dentistry, Suez Canal University. 
instruments are supposed to contact and plane the canal walls to debride the canal, but unfortunately complicated pulp space morphology makes total debridement and elimination of bacteria from the root canal system virtually impossible ${ }^{2}$. Therefore, effective irrigation together with instruments is mandatory to attain desired results of cleaning and shaping ${ }^{3}$.

Another factor that may influence cleaning and shaping, is the formation of smear layer during root canal instrumentation. The issue of smear layer hazards may be attributed to its possible contents of bacteria and their by-products, ability to hinder the intracanal irrigation and medicaments penetration into dentinal tubules and impede the filling materials adaptation to canal walls which makes its removal offers a superior outcome ${ }^{4,5}$.

The purpose of utilized root canal irrigating solutions while dealing with smear layer is twofold to remove/ dissolve its organic and inorganic components. As there is no single solution which has the ability to do so, the sequential use of organic and inorganic solvents has been recommended 6. Ethylenediamine tetraacetic acid (EDTA) and sodium hypochlorite $(\mathrm{NaOCl})$ solutions currently are the gold standard association for efficient cleaning of the root canals. EDTA acts upon the inorganic components of the smear layer via decalcifying the peri and intertubular dentine and leaving exposed collagen, then subsequent use of $\mathrm{NaOCl}$ dissolves the collagen ${ }^{7}$. They proved dentine surfaces substantially free from smear layer and provide a reduction in bacterial count ${ }^{8,9}$.

A newly introduced irrigant, Q $\operatorname{Mix}^{\mathrm{TM}}$ (a combination of EDTA, CHX, and Cetrimide), is advised as final rinse during root canal preparation. It proved ability for smear layer removal, biocompatibility and antibacterial potential efficacy when compared with other irrigants ${ }^{10-12}$. Also as a trend in all life branches to replace harmful chemicals by natural biocompatible alternatives; recently
Chitosan was produced as a natural polysaccharide obtained by the deacetylation of chitin that found in crab and shrimp shells. It has attracted attention in dentistry because of its biocompatibility, biodegradability and lack of toxicity ${ }^{13,14}$. It has an acidic $\mathrm{pH}$ and high chelating ability and proved smear layer removal ability ${ }^{15}$.

Unfortunately; it is proved that long-term use of these solutions is capable of altering the $\mathrm{Ca}$ : $\mathrm{P}$ ratio by removing the calcium ions $\left(\mathrm{Ca}^{2+}\right)$ present in hydroxyapatite crystals and promoting decalcification of dentin at approximate depths of 20-30 $\mu \mathrm{m}$ within $5 \mathrm{~min}{ }^{16,17}$. Thereby, the smear layer removal efficacy of root canal irrigating solutions may adversely affect the microhardness, permeability, and solubility characteristics of dentin ${ }^{18}$ which provides an indirect evidence of mineral loss or gain and consequently dentin fracture resistance ${ }^{19}$.

Therefore, this study aimed to evaluate and compare the smear layer removal ability of EDTA, Q Mix, and Chitosan as a final rinse and their subsequent effect on calcium ion loss and dentin microhardness.

\section{MATERIAL AND METHODS}

\section{Selection of teeth and preparation of root canals}

Forty freshly extracted human single-rooted maxillary incisors were selected for this study. Radiographs were taken to verify single canal. Using an ultrasonic scaler soft tissue and calculus were removed from teeth surfaces. Crowns were removed leaving standardized $16 \mathrm{~mm}$ length of root samples, and then stored in sterile saline solution at room temperature all over the study ${ }^{20}$. Working length was determined using\#10 K-file (Mani Inc, Japan) introduced into each canal until it was just visible at the apical foramen then subtracting $1 \mathrm{~mm}$ from this measurement.

Root samples were mounted in an irrigant 
collection apparatus similar to that described by Meyers and Montgomery ${ }^{21}$. Root samples were forced in holes created within the rubber cover of the glass vials, fixed using cyanoacrylate leaving only $1 \mathrm{~mm}$ of the root samples out while the remainder of the root sample suspended in the glass vial. Root canals preparation were done using the ProTaper Next system (Dentsply Maillefer, New York, USA) used with endodontic motor (X-Smart, Dentsply Maillefer, New York, USA) according to the manufacturer's recommendations at 300 RPM $12 \mathrm{Ncm}$ torque up to size 40/06. In all samples, 5 $\mathrm{mL}$ of $2.25 \%$ sodium hypochlorite was used after each file, for a total quantity of $20 \mathrm{~mL}$ by using a 30-gauge side-vented needle (Dentsply Maillefer, Shanghai, China) that was inserted into each canal $1 \mathrm{~mm}$ short of the working length. The root samples were divided randomly into four groups $(n=10)$ according to the irrigating solution used as a final rinse as follow:

Group A: $5 \mathrm{~mL}$ of $2.25 \%$ sodium hypochlorite (control group),

Group B: $5 \mathrm{~mL}$ of $17 \%$ EDTA irrigation (Merck, Germany),

Group C: $5 \mathrm{~mL}$ of QMix 2in1 (Dentsply, Tulsa Dental, OK, USA), and

Group D: $5 \mathrm{~mL}$ of $0.2 \%$ Chitosan was prepared by dissolving $0.2 \mathrm{~g}$ of Chitosan powder (Acros Organics, Geel, Belgium; degree of deacetylation $>90 \%$ ) in $100 \mathrm{~mL}$ of $1 \%$ acetic acid. The mixture was agitated using a magnetic agitator for $2 \mathrm{~h}$ to obtain homogenous clear solution.

\section{Calcium ions loss in final rinse}

$1 \mathrm{~mL}$ of saline irrigation was used before using final rinse to avoid interaction. A bent 19-gauge needle was forced alongside the rubber stopper of the glass vial to act as a drainage cannula, creating a balance between the air pressure inside and outside in order to allow final rinse collection in the glass vials ${ }^{21}$. Root canal samples were irrigated using the selected final rinse ( $5 \mathrm{~mL}$ each) with a 30 -gauge side-vented needle (Dentsply Maillefer, Shanghai, China) inserted into each canal $1 \mathrm{~mm}$ short of the working length. $1 \mathrm{~mL} / \mathrm{min}$ were injected to allow its collection in the glass vials through root apices. The collected solutions were evaluated at Toxicology and Micro-analytical Research Unit, Suez Canal University to quantify calcium ion release recorded as ppm using an atomic absorption spectrophotometer (ASS, Perkin/Elmer 2380 AA, USA).

\section{Smear layer removal evaluation}

Root samples were irrigated using $1 \mathrm{~mL}$ of saline then removed from the rubber cover of the glass vials. The forty root samples were longitudinally grooved on the external buccal and lingual surfaces with a diamond disk and split carefully with the use of a fine osteotome. Absorbent paper points were left inside the root canals to prevent the dentin dust coming from the external cut, from penetrating into root canal walls. One half of each sample was examined at the cervical, middle and apical thirds using Environmental Scanning Electron Microscope ESEM (FEI Quanta 250 FEG, Berlin, Germany) at $\times 1500$ magnification, and digital images were recorded then.

Then, smear layers were calculated using Image J program (U.S. National Institutes of Health, Bethesda, Maryland, USA) according to a scoring system developed by Torabinejad et al ${ }^{22}$; score 1: No smear layer - No smear layer was detected on the surface of the root canal, and all tubules were open, score 2: Moderate smear layer - No smear layer on root canal walls but tubules contained debris, Score 3: Heavy smear layer - smear layer covered the root canal wall surface and tubules.

\section{Dentin microhardness}

The remaining half of each sample was embedded in acrylic block, labeled, and dentin surface was flattened and sequentially polished through a wet 
grinding using 400,600, and 1200-grit $\mathrm{SiC}$ abrasive papers (Buehler). Microhardness testing was carried out using a microhardness tester Tukon 1102 (Wilson Instrument, Norwood, MA) with a Vickers diamond indenter. Indentations were made with the long axis of the diamond indenter perpendicular to the dentin surface in a microhardness testing machine. For each specimen, three indentations were made along a line approximately $0.5 \mathrm{~mm}$ from the root canal space at three different dentin levels (the inner, middle, and outer dentin), for a total of nine indentations per each specimen using a load of $50 \mathrm{~g} / 10 \mathrm{sec}^{23,16}$. After the load was removed, the diamond-shaped indentations were carefully observed in an optical microscope with a digital camera and image analysis software, allowing the accurate digital measurement of their diagonals. The average length of the two diagonals (usually to the nearest $0.1-\mu \mathrm{m}$ ) was used to calculate the microhardness value ${ }^{24}$. The representative hardness value for each level was obtained as the average of the results for the three indentations.

\section{Statistical analysis}

All quantitative data (microhardness and calcium ion loss) were explored for normality assumption using Shapiro wilk test. Data were considered normally distributed if $\mathrm{p}>0.05$. Test of normality revealed that all the present data assumed normality. Therefore ordinary parametric one way analysis of variance ANOVA test was used for analyzing differences among tested groups. Games-howell test was used for Ca ion release and Tucky post hoc test was used for microhardness when data ANOVA test was significant.

For non-parametric data (smear layer scores); Kruskal-Wallis test was used to compare between the irrigant materials and different levels of root canal. Dunn's test was used for pair-wise comparisons when Kruskal-Wallis test is significant.
The significance level was set at $\mathrm{P} \leq 0.05$. Statistical analysis was performed with IBM (IBM Corporation, NY, USA.), SPSS (SPSS, Inc., an IBM Company) Statistics Version 20 for Windows.

\section{RESULTS}

\section{Smear layer removal evaluation}

$\mathrm{NaOCl}$ did not show any ability to remove smear layer. A heavy smear layer was noted on the three levels of the root canal. The three chelating agents used as a final rinse significantly removed smear layer from the root canal better than $\mathrm{NaOCl}$. At the cervical third there was no statistically significant difference between EDTA, QMix, and Chitosan, while at the middle and apical thirds QMix showed the significantly highest smear layer removal ability followed by Chitosan then EDTA, with no statistically significant difference between them (Figure. 1)

\section{Calcium ions loss in final rinse}

According to the statistical evaluation of the $\mathrm{Ca}$ ion loss, there were no statistically significant differences between EDTA, QMix, and Chitosan. They were statistically higher than $\mathrm{NaOCl}$ which showed the lowest $\mathrm{Ca}$ ion loss (Table 1).

\section{Dentin microhardness}

A reverse correlation was noted between dentin microhardness and $\mathrm{Ca}^{2+}$ release. There was a statistically significant difference between all tested irrigating solutions at the three levels of the root canal. $\mathrm{NaOCl}$ recorded the statistically significantly highest dentin microhardness followed by Chitosan, QMix and then EDTA which recorded the lowest dentin microhardness. Regarding different levels of the root canal; apical third recorded the highest value of dentin microhardness followed by the middle then the cervical third (Table 2). 


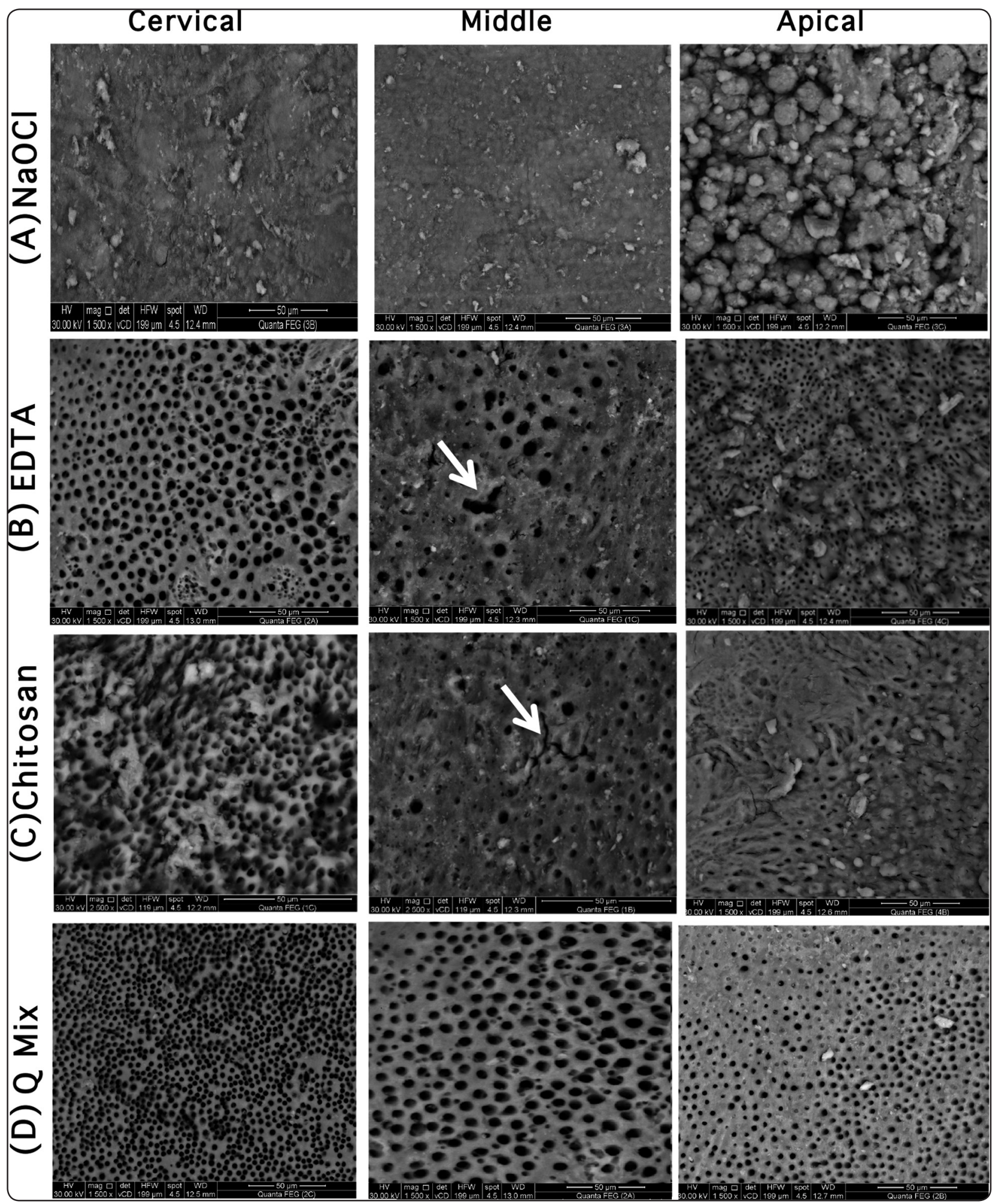

Fig. (1) Scanning electron microscope photographs at 1500X showing; root samples treated with sodium hypochlorite (A), EDTA (B), Chitosan (C) and Q Mix (D) at different levels of root canal (cervical, middle, and apical). Heavy smear layer at all root thirds was noticed in group A. In group B and C, complete smear layer removal and patent dentinal tubules especially at cervical root third, followed by middle then apical root third which showed the least ability of smear layer removal with evident smear layer (Arrow denoting erosive effect of EDTA and Chitosan). Q Mix showed the highest ability of smear layer removal and patent dentinal tubules at cervical and middle root thirds followed by apical root third. 
TABLE (1) Means and standard deviations (SD) of Calcium ion loss, expressed as ppm, in irrigation solutions.

\begin{tabular}{|c|c|c|c|c|c|}
\hline & EDTA & QMix & Chitosan & NaOCl & \multirow{2}{*}{ P-value } \\
\cline { 2 - 5 } & Mean \pm SD & Mean \pm SD & Mean \pm SD & Mean \pm SD & \\
\hline $\mathrm{Ca}^{2+} \operatorname{loss}(\mathrm{ppm})$ & $516.090^{\mathrm{a}} \pm 36.008$ & $515.202^{\mathrm{a}} \pm 35.793$ & $499.641^{\mathrm{a}} \pm 34.584$ & $0.493^{\mathrm{b}} \pm 0.090$ & $0.001^{*}$ \\
\hline
\end{tabular}

Means with different superscript letters were statistically significant at $p<0.05$.

TABLE (2) Means and standard deviations (SD) of dentin microhardness of the three levels of root canal after using different irrigating solutions.

\begin{tabular}{|c|c|c|c|c|c|}
\hline IRRIGANT & EDTA & Chitosan & Q MIX & $\mathrm{NaOCL}$ & \multirow{2}{*}{$P$-value } \\
\hline LEVE & Mean \pm SD & Mean \pm SD & Mean \pm SD & Mean \pm SD & \\
\hline Cervical & $55.24^{\mathrm{dC}} \pm 0.456$ & $63.80^{\mathrm{bC}} \pm 0.628$ & $60.86^{\mathrm{CC}} \pm 0.151$ & $70.92^{\mathrm{aB}} \pm 0.832$ & $0.001 *$ \\
\hline Middle & $59.68^{\mathrm{dB}} \pm 0.303$ & $65.00^{\mathrm{bB}} \pm 0.494$ & $63.02^{\mathrm{cB}} \pm 0.491$ & $66.84^{\mathrm{aC}} \pm 1.224$ & $0.001 *$ \\
\hline Apical & $65.24^{\mathrm{dA}} \pm 0.577$ & $73.88^{\mathrm{bA}} \pm 0.798$ & $69.72^{\mathrm{cA}} \pm 1.188$ & $76.86^{\mathrm{aA}} \pm 1.856$ & $0.001 *$ \\
\hline$P$-value & $0.001 *$ & $0.001 *$ & $0.001 *$ & $0.001 *$ & \\
\hline TOTAL & $180.16^{\mathrm{d}} \pm 0.445$ & $209.72^{b} \pm 1.575$ & $193.60^{c} \pm 0.851$ & $214.62^{\mathrm{a}} \pm 2.063$ & 0.001 \\
\hline
\end{tabular}

Means with different superscript small letters in the same row were statistically significant at $p<0.05$.

Means with different superscript capital letters in the same column were statistically significant at p<0.05.

\section{DISCUSSION}

In demands to achieve successful endodontic therapy, an effective chemo-mechanical preparation as well as three-dimensional obturation of the root canal system is mandatory ${ }^{25}$. On account of instrumentation procedure using various root canal instruments a smear layer is formed ${ }^{26}$ leading to incomplete disinfection of dentin walls and increase post obturation microleakage ${ }^{27}$. In the current study, Environmental Scanning Electron Microscope (ESEM) was utilized to evaluate smear layer removal ability of three different final rinses. It retains all of the performance advantages of a conventional SEM, but removes the high vacuum constraint on the sample environment, can image wet and non-conductive samples without modification or preparation and eliminates the need for conductive coating ${ }^{28}$.

Root samples irrigated using $\mathrm{NaOCl}$ alone showed a statistically significant heavy smear layer on coronal, middle, and apical thirds of dentin wall than other irrigating solutions used. Ineffectiveness of $\mathrm{NaOCl}$ alone to remove the smear layer was in accordance with previous investigations 22, 29, 30 which might be attributed to its low physicochemical action that is limited to the organic component of the smear layer ${ }^{31}$. So, in order to increase dentin permeability chelating agents play a major role via removing smear layer ${ }^{32,33}$.

In this study, 17\% EDTA final rinse coupled with $\mathrm{NaOCl}$ showed excellent smear layer removal, mainly in the middle and cervical thirds but showed 
less effectiveness in the apical third of root canals, also dentin erosion was noticed. These findings were in agreement with Torabinejad et al ${ }^{22}$ and Mancini et $\mathrm{al}^{34}$ who reported effectiveness of EDTA in smear layer removal only in coronal and middle thirds but not in the apical third. This might be inferred to the high surface tension of EDTA $(46.8 \mathrm{~mJ} / \mathrm{m} 2){ }^{35}$. In addition, chelating action of EDTA is effective at a neutral $\mathrm{pH}$ and its efficacy decreases over time due to the decrease in $\mathrm{pH}$ subsequent to the exchange of calcium from dentin by hydrogen ${ }^{36}$. On the other hand, the root canal dentin in the apical third is reported to be sclerosed ${ }^{37}$; hence EDTA requires not less than 15 min for optimal action on sclerosed dentin in the apical third which adversely lead to dentin erosion ${ }^{38}$.

Also, $0.2 \%$ Chitosan was as efficient as $17 \%$ EDTA in removing smear layer from the cervical and middle thirds of the root canal, and rather better than EDTA in the apical third with no significant difference. These results were in accordance with Silva et al ${ }^{15}$ and Pedro et al ${ }^{39}$ where $0.2 \%$ Chitosan solution showed smear layer removal ability better than all tested chelating agents at coronal, middle and apical thirds. Chitosan chelates calcium ions through "adsorption and ionic exchange" processes, and is a hydrophilic polymer that eases intimate contact and adsorption with root canal dentin. In addition, it is a cationic solution owned a large number of free hydroxyl and amino groups that is responsible for the ionic interaction between the dentin calcium ions and the chelating agent ${ }^{40}$. Moreover, Chitosan is insoluble in water and it was dissolved in $1 \%$ acetic acid to form a solution. In an acid medium, the amino groups in Chitosan polymer are protonated, resulting in attraction of other molecules allowing more adsorption to root dentin and deeper delivery into dentinal tubules which might supplement its chelating efficacy ${ }^{41,42}$.

Concomitantly; QMix also removed smear layer as effectively as 17\% EDTA in both cervical and middle root thirds in accordance with Stojicic et al ${ }^{25}$ and Dai et al ${ }^{43}$. Moreover, QMix showed significantly higher smear layer removal ability in the apical third among the tested solutions. This high ability of QMix to remove smear layer might be attributed to the added surface active agent in QMix that lowers the surface tension to $36.4 \mathrm{~mJ} / \mathrm{m} 2$ which in turn leads to better penetration of the irrigant in the root canal ${ }^{44}$ and increases wettability ${ }^{25,45}$. Also, CHX content of QMix offers the rinse a unique property "substantivity" which enables it to adsorb onto dentin and hence more prolonged action ${ }^{46}$. Also; Dai et al ${ }^{43}$ proved the comparable effectiveness of QMix to 17\% EDTA final rinse in term of smear layers removal from the entire root canal wall in straight root canals.

In the current study apical one third showed the least smear layer removed for tested rinses which was attributed to its limited size, complex anatomy ${ }^{47}$, decreased permeability and sclerotic nature of the dentin ${ }^{48}$. On the other hand, slow injection and passive irrigation technique utilized in this study offers limitations in the ability of the irrigant to reach and exchange fluids in this area ${ }^{49}$.

Removal of the smear layer and remaining pulp debris may in turn leads to calcium ions loss from root canal dentin that negatively affects its microhardness, and altering the mechanical and chemical properties 50,19. Atomic absorption spectroscopy was used in this study to determine the concentration of calcium ion in each sample of used final rinse to evaluate its demineralization effect. It is a single element technique which is less costeffective than newer multi-element techniques ${ }^{51}$. Meanwhile, Vickers microhardness test was done to evaluate the surface changes in the treated dentin wall of root canal. It can provide indirect evidence of mineral loss effect on the dental hard tissues due to the suitability and practicality for evaluating surface changes of deeper dental hard tissues rather than Knoop hardness tester which used for superficial dentin at $0.1 \mathrm{~mm}^{52}$. 
Irrigation with $2.25 \% \mathrm{NaOCl}$ without using chelating irrigating solution as a final rinse abstracted the significantly least mean amount of calcium ions from the dentin $(0.493 \mathrm{ppm})$ among used final rinses. This was in agreement with Lottanti et al ${ }^{53}$ and Taneja et $a 1^{54}$ who reported that $\mathrm{NaOCl}$ hardly eluted any $\mathrm{Ca}$ ions from root canal dentin. The calcium ion loss seen in this group could be explained as a result of mechanical flushing action of the irrigating solution on the formed smear layer on root dentin ${ }^{5}$. On the contrary, 17\% EDTA final rise showed the maximum mean $\mathrm{Ca}$ ions loss from root canal dentin (516.09 ppm) among all studied groups, as it has the ability to sequester metal ions such as $\mathrm{Ca}^{2+}$ from root canal dentin, thereafter forms soluble calcium chelates after being bound by EDTA ${ }^{55,56}$.

Also QMix final rinse showed a high Ca ions loss (515.202 ppm) which was attributed to its EDTA content, that makes its effect on root dentin could be almost similar to EDTA ${ }^{35}$. These results were in agreement with Dai et $\mathrm{al}^{43}$ who proved that smear layer removing ability of QMix was comparable to that of $17 \%$ EDTA. The representative composition of QMix is $(13.6 \%$ by weight EDTA, $0.1 \%$ by weight chlorhexidine, and $0.1 \%$ by weight cetrimide in distilled water) ${ }^{57}$. Considering that EDTA is present in smaller amount in QMix composition so, its effective $\mathrm{Ca}$ ions chelation may be explained by its surface active agent composition enables its wettability and allows for deeper penetration of the irrigating solution which in turn chelates more $\mathrm{Ca}$ ions from root canal dentin ${ }^{44}$.

In the present study, $0.2 \%$ Chitosan was associated with high mean amounts of $\mathrm{Ca}$ ions release (499.641 ppm) which insignificantly lower than that released by both EDTA and QMix final rinses. Chitosan chelating action is subsequent to adsorption and ionic exchange for the formation of complexes between Chitosan and the metallic ions 23. Currently, there are two theories to explain the
Chitosan chelating action. The first, known as "the model of the bridge ", is based on that one metallic ion is bind to two or more amino groups of one Chitosan chain ${ }^{58}$. The second, stating that only one amino group of the Chitosan chain is involved in the binding, that being the metallic ion "anchored" to ${ }^{59}$. The results of root canal dentin demineralizing action of Chitosan were in consonance with the results of Fábio et al ${ }^{39}$ and Silva et al ${ }^{15}$.

A considerable negative correlation between calcium ions loss from root dentin and its microhardness was found in all groups. Root canals irrigated with $\mathrm{NaOCl}$ alone showed the highest dentin microhardness mean values in cervical, middle, and apical root thirds which were significantly different from the other groups. The low microhardness associated with experimental groups could be related to consequent use of chelating agents after $\mathrm{NaOCl}$, as the chelating agents are capable of demineralizing the inorganic calcified portion of the root canal wall which negatively affects its microhardness ${ }^{35}$. Also many studies ${ }^{16,60-62}$ showed that $\mathrm{NaOCl}$ promotes dissolution of dentin organic portion while chetaling agents facilitate chelation of its inorganic portion and consequently it showed less microhardness. Results of this study were in concurrence with Panighi and G'Sell ${ }^{63}$ and Taneja et al ${ }^{54}$ who found a simple linear correlation between microhardness and calcium ion concentration of dentin.

For QMix, the association of cetrimide with EDTA might be responsible for facilitating EDTA penetration into dentinal tubules, causing reduction in dentin microhardness without noticed dentin erosion ${ }^{64-66}$. Chitosan although used in a low concentration $(0.2 \%)$, it produced a comparable chelating effect to EDTA, with less dentin microhardness reduction. This could be due to the substance itself not due to the $1 \%$ acetic acid used in preparation of Chitosan. This was proved by Spanó et al ${ }^{68}$ who found that the capacity of 
5\% acetic acid for reducing dentin microhardness, and removing the smear layer and chelating calcium ions in the root canal was insignificant in relation to $15 \%$ EDTA and $10 \%$ citric acid.

In the current study, the apical third recorded the lowest reduction in dentin microhardness in all groups. This could be attributed to the composition of this region with low content of noncollagenous organic Matrix. As chelating solution reduces the mineral and noncollagenous protein component of the dentin, leading to surface softening ${ }^{69}$, so it showed lower degree of decalcification in this part of the root ${ }^{70}$. Also, reduced flow and backflow of the irrigant in the apical third should be considered as a factor in reduction of irrigation solutions effect at apical third ${ }^{71}$. The higher reduction at cervical and middle root thirds could be inferred to inverse correlation between dentin microhardness and tubular density ${ }^{23}$, as Carrigan et al ${ }^{72}$ proposed that tubule density decreased from cervical to apical dentin.

In this study, more reduction in dentin microhardness was noticed at the cervical third than at the middle third which could be due to quantity and contact time of irrigant that might be more at the cervical third producing more effect. This was in parallel to smear layer removal results; where the cervical root third showed less smear layer than the middle third. It was proved that the size of the canal lumen at the cervical third may improve removal of debris, and allow adequate cleaning and penetration of the solution ${ }^{65}$.

\section{CONCLUSION}

Under the circumstances of this study, it was concluded that:

- All tested irrigation solutions (EDTA, QMix, and Chitosan) removed favorably smear layer particularly from the middle and cervical thirds of the root canal.
- The greater the smear layer was removed, the higher the $\mathrm{Ca}^{2+}$ loss from root canal dentin and the lower the dentin microhardness. (inverse correlation)

- It was difficult to completely remove the smear layer from the apical third, so it remained the highest microhardness.

- Although non significantly different, QMix had the higher smear layer removal ability, while less reduction in dentin microhardness.

\section{REFERENCES}

1. Naïr P, Henry S, Cano V, Vera J. Microbial status of apical root canal system of human mandibular first molars with primary apical periodontitis after one visit endodontic treatment. Oral Surg Oral Med Oral Pathol Oral Radiol Endo 2005; 99: 231-52.

2. Ricucci D, Langeland, K. Apical limit of root canal instrumentation and obturation, part 2: A histological study. Inter Endod J 1988; 31, 394-409.

3. Gomes B, Ferraz C, Vianna M, Berber V, Teixeira F, et al. In vitro antimicrobial activity of several concentrations of sodium hypochlorite and chlorhexidine gluconate in the elimination of Enterococcus faecalis. Int Endod J 2001; 34: 424-8.

4. Oskan T, Aktener BO, Sen BH, Tezel H. The penetration of root canal sealers into dentinal tubules. A scanning electron microscope study. Int Endod J. 1993;26:301-5.

5. Putzer P, Hay H, Günay H. Highly concentrated EDTA gelimproves cleaning efficiency of root canal preparation in vitro. Clin Oral Investig 2008;12:319-4.

6. Baumgartner JC, Brown CM, Mader CL, Peters DD, Shulman JD. A scanning electron microscopic evaluation of root canal debridement using saline, sodium hypochlorite, and citric acid. J Endod 1984;10, 525-31.

7. Yamada RS, Armas A, Goldman M, Lin PS. A scanning electron microscopic comparison of a high volume final flush with several irrigating solutions: Part 3. Journal of Endodontics 1983;9: 137-42.

8. Foschi F, Nucci C, Montebugnoli L, Marchiorni S, Breschi L. SEM evaluation of canal wall dentin following use of M two and Protaper NiTi rotary insruments. Int Endod J 2004;37:832-9 
9. Dagna A, Ariola CR, Florindi F, Scribnate A, Saino E. In vitro evaluation of antimicrobial efficacy of endodontic irrigants. Int J Artif Organs 2011; 34:914-9.

10. Stojicic S, Shen Y, Qian W, Johnson B, Haapasalo M. Antibacterial and smear layer removal ability of a novel irrigant, QMix. Int Endod J 2012;45:363-71

11. Eliot C, Hatton JF, Stewart GP, Hildebolt CF, Jane Gillespie M, Gutmann JL. The effect of the irrigant QMix on removal of canal wall smear layer: An ex vivo study. Odontology 2014;102:232-40.

12. Chandrasekhar V, Amulya V, Rani VS, Prakash TJ, Ranjani AS, Gayathri Ch. Evaluation of biocompatibility of a new root canal irrigant Q Mix ${ }^{\mathrm{TM}} 2$ in 1- An in vivo study. $\mathrm{J}$ Conserv Dent 2013;16:36-40

13. Elsaka S, ElnaghyA. Antibacterial activity of calcium hydroxide combined with Chitosan solutions and the outcomes on the bond strength of RealSeal sealer toradicular dentin. J Biomed Res 2012;26:193-9.

14. DaSilva L, Finer Y, Friedman S, Basrani B, Kishen A. Biofilm formation within the interface of bovine root dentin treated with conjugated Chitosan and sealer containing Chitosan nanoparticles. J Endod 2013; 39:249-53

15. Silva P, Guedes D, Nakadi F,Pecora J, Cruz-Filho A.Chitosan: a new solution for removal of smear layer after root canal instrumentation. Int Endod J 2013;46:332-8.

16. Saleh AA, Ettman WM. Effect of endodontic irrigation solutions on microhardness of root canal dentin. J Dent 1999;27:43-6.

17. Ari H, Erdemir A, Belli S. Evaluation of the effect of endodontic irrigation solutions on the microhardness and the roughness of root canal dentin. J Endod. 2004;30:792-5.

18. Sayin TC, Cehreli ZC, Deniz D, Akcay A, Tuncel B, Dagli F, Gozukara H, Kalayci S. Time-dependent decalcifying effects of endodontic irrigants with antibacterial properties. J Endod. 2009;35:280-3.

19. Sayin TC, Serper A, Cehreli ZC, Otlu HG. The effect of EDTA, EGTA, EDTAC, and tetracycline- $\mathrm{HCl}$ with and without subsequent $\mathrm{NaOCl}$ treatment on the microhardness of root canal dentin. Oral Surg Oral Med Oral Pathol Oral Radiol Endod. 2007;104:418-24.

20. Scelza MF, Pierro V, Scelza PM. Effect of three different time periods of irrigation with EDTA-T,EDTA, and citric acid on smear layer removal. Oral Surg Oral Med Oral Pathol Oral Radiol Endod 2004;98:499-503
21. Myers GL, Montgomery S. A comparison of weights of debris extruded apically by conventional filing and canal master techniques. J Endod 1991;17:275-9.

22. Torabinejad M, Khademi AA, Babagoli J, Cho Y, Johnson WB, Bozhilov K, et al. A new solution for the removal of the smear layer. J Endod 2003;29:170-5.

23. Pashley D, Okabe A, Parham P. The relationship between dentin microhardness and tubule density. Endod Dent Traumatol 1985;1:176-9.

24. De-Deus G, Paciornik S, Mauricio MHP. Evaluation of the effect of EDTA, EDTAC and citric acid on the microhardness of root dentin. Int Endod J 2006;39:401-7.

25. Hashem AA, Ghoneim AG, Lutfy RA, Fouda MY. The effect of different irrigating solutions on bond strength of two root canal-filling systems. J Endod 2009;35:537-40.

26. McComb D, Smith DC. A preliminary scanning electron microscopic study of root canals after endodontic procedures. J Endod 1975;1: 238-42.

27. Mozayeni MA, Zadeh YM, Paymanpour P, Ashraf H, Mozayani M. Evaluation of push-out bond strength of AH26 sealer using MTAD and combination of $\mathrm{NaOCl}$ and EDTA as final irrigation. Dent Res J 2013;10:359-63.

28. McDonald AM. Environmental scanning electron microscopy. Mater World 1998;6:399-401.

29. Mozayeni MA, Javaheri GH, Poorroosta P, Ashari MA, Javaheri HH. Effect of 17\% EDTA and MTAD on intracanal smear layer removal: a scanning electron microscopic study. Aust Endod J 2009;35:13-7

30. Ulusoy Ol, Gorgul G. Effects of different irrigation solutions on root dentin microhardness, smear layer removal and erosion. Aust Endod J; 2011:1-7

31. Mohammadi Z. Sodium hypochlorite in endodontics: an update review. Int Dent J 2008;58:329-41

32. Shahravan A, Haghdoost AA, Adl A, Rahimi H, Shadifar F. Effect of smear layer on sealing ability of canal obturation: A systematic review and meta-analysis. J Endod 2007;33:96-105.

33. Silva P.V., Guedes D.F., Pécora J.D., da Cruz-Filho A.M. Time-dependent effects of Chitosan on dentin structures. Braz Dent J 2012;23:357-61.

34. Mancini M, Armellin E, Casaglia A, CerroniL, Cianconi L. A comparative study of smear layer removal and erosion in apical intraradicular dentin with three irrigating solu- 
tions: a scanning electron microscopy evaluation. J Endod. 2009 ;35:900-3

35. Shahvaran A, Haghdoost A.A, Adl A, Rahimi H, Shadifar F. Effect of smear layer on sealing ability of canal obturation: a systematic review and meta-analysis. J Endod 2007;33:96-105

36. Hülsmann M, Heckendorff M, Lennon A. Chelating agents in root canal treatment: mode of action and indications for their use. Int Endod J 2003;36:810-30

37. Paque F, Luder H.U, Sener B. Tubular sclerosis rather than the smear layer impeded dye penetration in to the dentin of endodontically instrumented root canals. Int Endod J 2006;39:18-25

38. Zehnder M. Root canal irrigants. J Endod 2006; 32:389-98

39. Fábio LMP, Laura M, Gilberto SF, Orlando AG, Thiago MP, and Alvaro HP. Assessment of the Amount of Calcium Ions Released after the use of Different Chelating Agents and Agitation Protocols. Open Dent J. 2017 ;22:133-9.

40. Zhang J, Xia Z, Liu P, Cheng Q, Tahirou T, Gu W. Chitosan modification and pharmaceutical/ Biomedical Applications. Mar Drugs 2010;8:1962-87

41. Shrestha A, Kishen A. The effect of tissue inhibitors on the antibacterial activity of Chitosan nanoparticles and photodynamic therapy. J Endod 2012;38:1275-8

42. Rhazi M, Desbrières J, Tolaimate A, Rinaudo M, Vottero $\mathrm{P}$, Alagui A. Influence of the nature of the metal ions on the complexation with Chitosan. Application to the treatment of liquid waste. Eur Polym J 2002;38:1523-30

43. Dai L, Khechen K, Khan S et al. The effect of QMix, an experimental antibacterial root canal irrigant, on removal of canal wall smear layer and debris. J Endod 2011; 37:80-4.

44. Abou-Rass M, Patonai FJ Jr .The effects of decreasing surface tension on the flow of irrigating solutions in narrow root canals. Oral Surgery Oral Medicine Oral Pathology 1982;53:524-6.

45. Giardino L, Ambu E, Becce C, Rimondini L, Morra M. Surface tension comparison of four common root canal irrigants and two new irrigants containing antibiotic. J En$\operatorname{dod} 2006 ; 32: 1091-3$.

46. Ferretti GA, Brown AT, Raybould TP, Lillich TT. Oral antimicrobial agents -chlorhexidine. NCI Monographs 1990;9:51-5.
47. Ruddle CJ. Hydrodynamic disinfection tsunami endodontics. Dent Today 2007;26:1-9.

48. Ribeiro RG, Marchesan MA, Silva RG, Sousa-Neto MD, Pécora JD. Dentin permeability of the apical third in different groups of teeth. Braz Dent J 2010;21:216-19.

49. Baugh D, Wallace J. The role of apical instrumentation in rootcanal treatment: a review of the literature. J Endod 2005;31:333-40.

50. Calt S, Serper A. Smear layer removal by EGTA. J Endod 2000;26:459-61.

51. Machado-Silveiro LF, González-López S, González-Rodríguez MP. Decalcification of root canal dentin by citric acid, EDTA and sodium citrate. Inter Endod J 2004; $37: 365-9$.

52. Fuentes V, Toledano M, Osorio R. Microhardness of superficial and deep sound human dentin. J Biomed Mater Res A 2003;6: 850-3.

53. Lottanti S, Gautschi H, Sener B, Zehnder M. Effects of ethylenediaminetetraacetic, etidronic and peracetic acid irrigation on human root dentin and the smear layer. Int Endod J 2009;42:335-43.

54. Taneja S, Kumari M, Anand S. Effect of QMix, peracetic acid and ethylenediaminetetraacetic acid on calcium loss and microhardness of root dentin. J Conserv Dent 2014;17:155-8.

55. Harris DC. New York: WH. Quantitative Chemical Analysis. Freeman Company; 2007

56. Von der Fehr FR, Nygaard-Ostby B. Effect of EDTAC and sulfuric acid on root canal dentin. Oral Surg Oral Med Oral Pathol 1963;16:199-205.

57. DENTSPLY Tulsa Dental Specialties, Patent EP 2259784 A1, 2010.

58. Blair HS, Ho TC. Studies in the adsorption and diffusion of ions in Chitosan. J Chem Technol Biotechnol 1981; 31:6-10.

59. Domard A. pH and c.d. measurements on a fully deacetylated Chitosan: application to CuII-polymer interactions. Int J Biol Macromol 1987;9:98-104.

60. Sousa SMG, Silva TL. Demineralization effect of EDTA, EGTA, CDTA and citric acid on root dentin: a comparative study. Braz Oral Res 2005;19:188- 92

61. Khedmat S, Shokouhinejad N. Comparison of the efficacy of three chelating agents in smear layer removal J Endod 2008;34:599-602 
62. Dasilva L A, Sanguino A C, Rocha C T, Leonardo M R, Silva R A. Scanning electron microscopic preliminary study of the efficacy of smear clear and EDTA for smear layer removal after root canal instrumentation in permanent teeth J Endod. 2008;34:1541-4

63. Panighi M, G'Sell C. Effect of the tooth microstructure on the shear bond strength of a dental composite. J Biomed Mater Res 1993;27:975-81.

64. Poggio C, Dagna A, Colombo M, Scribante A, Chiesa M. Decalcifying efficacy of different irrigating solutions: effect of cetrimide addition. Braz Oral Res 2014;28:1-6.

65. Peters O.A., Barbakow F. Effects of irrigation on debris and smear layer on canal walls prepared by two rotary techniques: a scanning electron microscopic study. J Endod 2000;26:6-10

66. Baldasso FER, Roleto L, Silva VDD, Morgental RD, Kopper PMP. Effect of final irrigation protocols on microhardness reduction and erosion of root canal dentin. Braz Oral Res 2017;31:e40

67. Nikhil V, Jaiswal SH, Bansal P, Arora R, Raj SH, and Malhotra P. Effect of phytic acid, ethylenediaminetetraace- tic acid, and Chitosan solutions on microhardness of the human radicular dentin. J Conserv Dent 2016; 19: 179-83.

68. Spanó JC, Silva RG, Guedes DF, Sousa-Neto MD, Estrela C, Pécora JD. Atomic absorption spectrometry and scanning electron microscopy evaluation of concentration of calcium ions and smear layer removal with root canal chelators. J Endod 2009;35:727-30.

69. Kawasaki K, Ruben J, Stokroos I, Takagi O, Arends J. The remineralization of EDTA-treated human dentin. Caries Res 1999;33:275-80.

70. Verdelis K, Eliades G, Oviir T, Margelos J. Effect of chelating agents on the molecular composition and extent of decalcification at cervical, middle and apical root dentin locations. Endod Dent Traumatol 1999;15:164-70.

71. Doğan H, Qalt S. Effects of chelating agents and sodium hypochlorite on mineral content of root dentin. J Endod 2001; 27:578-80.

72. Carrigan PL, Morse DR, Furst ML, Sinai IH. A scanning electron microscopic evaluation of human dentinal tubules according to age and location. J Endod 1984;10:359-63. 